\title{
Propriedades químicas e de pasta dos amidos de trigo e milho fosforilados
}

\author{
Chemical and past properties of wheat and maize starches phosphorilads
}

Williams Pereira BATISTA²*, Claudio Ernani Mendes da SILVA², Maria Conceição LIBERATO ${ }^{1}$

\begin{abstract}
Resumo
Os amidos de trigo e milho foram fosforilados com tripolifosfato de sódio (TPS) em 4 diferentes níveis de adição. As viscosidades máximas da pasta de trigo aumentaram e as temperaturas de pasta diminuíram à medida que cresceram os graus de substituição de grupos fosfato, enquanto que, para o amido de milho, as viscosidades máximas aumentaram e as temperaturas de pasta mantiveram-se constantes. Os amidos fosforilados (amido/água 1:10) foram submetidos à cocção $\left(100,0^{\circ} \mathrm{C} / 1,0\right.$ minuto), secagem $\left(40,0^{\circ} \mathrm{C} / \sim 4,0 \%\right.$ de umidade) e moagem (diâmetro de partícula, $\Phi=0,149 \mathrm{~mm}$ ) para determinar o teor de amido resistente (AR). Para o menor grau de substituição de grupos fosfato no amido de trigo (0,0029), foi encontrado um teor de amido resistente de $30,46 \%$ e no amido de milho de $24,36 \%$. Para o maior grau de substituição no amido de trigo (0,0127), foi encontrado um teor de AR de 46,69\%, enquanto para o amido de milho, 28,40\%. O aumento do grau de substituição, em ambos os casos, parece induzir um aumento no teor de amido resistente, e a fosforilação com TPS mostrou ser um excelente método para produzir quantidades significativas de amido resistente tanto no amido de trigo como no amido de milho.

Palavras-chave: amido de trigo; amido de milho; fosforilação; reologia; amido resistente.
\end{abstract}

\begin{abstract}
Wheat and maize starches were phosphorylated with sodium tripolyphosphate (TPS) at 4 different levels of addition. The maximum viscosities of the wheat doughs formed were increased and the dough temperatures decreased as the degrees of substitution of phosphate groups were increased; while for the maize starch the viscosities were increased and the dough temperatures remained constant. The phosphorylated starches (starch/water, 1:10) were subjected to cooking $\left(100^{\circ} \mathrm{C} / 1\right.$ minute), followed by drying $\left(40^{\circ} \mathrm{C} / \sim 4.0\right.$ per cent moisture) and milling (particle diameter, $\Phi=0.149 \mathrm{~mm}$ ) to determine the resistant starch (RS) content. For the lowest degree of substitution of phosphate groups in wheat starch (0.0029), resistant starch content of 30.46 per cent was found, while for maize starch RS content of 24.36 per cent was found. For the highest degree of substitution in wheat starch (0.0127) 46.69 per cent of RS content was found; while for maize starch, RS content of 28.40 per cent was found. According to the results, the increase in the degree of substitution in both cases seems to induce an increase in the resistant starch content, and phosphorylation with TPS was shown to be an excellent method for producing significant quantities of resistant starch in both wheat and maize starch.

Keywords: wheat starch; corn starch; phosphorylation; rheology; resistant starch.
\end{abstract}

\section{Introdução}

Modificações químicas são frequentemente realizadas nos amidos para alterar suas propriedades naturais a fim de que eles possam ser utilizados em aplicações alimentícias ou industriais. Amidos quimicamente modificados têm suas propriedades físico-químicas alteradas quando comparadas com seus amidos naturais e apresentam modificações na estrutura química de algumas das unidades glucopiranosídicas do polímero. Essas modificações usualmente envolvem oxidação, esterificação, eterificação (RUTENBERG; SOLAREK, 1984), cloração, piroconversão e a introdução de ligações cruzadas (WURZBURG, 1989).

A fosforilação é um método muito usado para a modificação do amido em que a repulsão entre cadeias de amido adjacentes causadas pela introdução de grupos fosfato carregados negativamente reduz as associações entre cadeias e facilita a hidratação do amido (LIU; RAMSDEN; CORKE, 1999). Os grupamentos fosfato estão ligados covalentemente às moléculas de amilopectina e podem ser isolados de culturas de raízes e tubérculos, como no amido de batata que apresenta uma grande quantidade de fosfato orgânico e que garante à batata um elevado grau de substituição de fosfato (NODA et al., 2007). A presença de fósforo nas moléculas é um importante fator na variação das propriedades funcionais dos amidos, incluindo a gelatinização e retrogradação (KARIM et al., 2007).

Um dos tipos de modificação química mais utilizada com amidos naturais é a fosforilação com o tripolifosfato de sódio (TPS), por ser um sal relativamente barato, pela facilidade de execução do processo e pela produção de pastas com boa claridade (LIM; SEIB, 1993). A introdução de grupos fosfatos nas cadeias de amido causa a repulsão entre cadeias e aumenta sua hidratação (LIM; SEIB, 1993; LIU; RAMSDEM; CORKE, 1999), além de permitir a obtenção de amidos com alto teor de

Recebido para publicação em 22/2/2008

Aceito para publicação em 16/5/2009 (003211)

1 Coordenação do Curso de Química, Centro de Ciências e Tecnologia, Universidade Estadual do Ceará - UECE, CEP 60740-903, Fortaleza - CE, Brasil

${ }^{2}$ Departamento de Tecnologia de Alimentos, Universidade Federal do Ceará - UFC, CEP 60356-000, Fortaleza - CE, Brasil, E-mail: williamspereira@ig.com.br

${ }^{*}$ A quem a correspondência deve ser enviada 
amido resistente (LIBERATO, 2002), cuja importância tem se acentuado nos últimos tempos, em função de suas propriedades nutricionais.

A importância do amido resistente nas propriedades de pasta do amido fica evidente em estudos como o de Teixeira et al. (1998), em que o amido resistente de milho não apresentou temperatura de pasta. Sua viscosidade máxima foi muito baixa e quase igual à viscosidade mínima, indicando que ou as temperaturas aplicadas não foram capazes de alterar as interações entre as moléculas formadoras da rede cristalina ou o tratamento hidrotérmico destruiu a estrutura granular, cujo inchamento resulta no aumento da viscosidade.

Entretanto, o grau de substituição de grupos fosfatos entre os amidos para uma determinada temperatura é variável, sendo função do pH (LIU; RAMSDEM; CORKE, 1999) e da concentração (LIBERATO, 2002).

$\mathrm{Na}$ tentativa de comparar as propriedades de pasta e as vantagens da utilização dos amidos de trigo e milho em aplicações alimentícias em que esses amidos modificados por fosforilação podem ser utilizados na redução do valor calórico e do aumento de amido resistente de formulações, desenvolvemos o presente trabalho.

\section{Material e métodos}

\subsection{Materiais}

\section{Matérias-primas}

Amido de milho (Kimimo, Mossoró - RN) e amido de trigo, extraído de farinha de trigo comercial (Dona Benta, Fortaleza CE) de acordo com a metodologia descrita por Wolf (1964).

\subsection{Métodos}

\section{Caracterização dos amidos}

Para a determinação da composição centesimal da farinha de trigo, foram utilizadas as metodologias descritas pela American Association of Cereal Chemists (AACC, 1995) para determinação de umidade, de proteína, da fração mineral e da fração lipídica.

\section{Determinação da umidade}

Através de secagem em estufa (FABBE, modelo 119; São Paulo, SP, Brasil) a $130,0^{\circ} \mathrm{C}$ até peso constante, de acordo com método 44-15A da AACC (1995), em que foram pesados $2 \mathrm{~g}$ de amostra num cadinho previamente tarado, colocado descoberto em estufa por 1 hora.

Determinação da fração mineral

Determinada por calcinação em mufla (QUIMIS, modelo 318-21; São Paulo, SP, Brasil) a 550,0 ${ }^{\circ} \mathrm{C}$, de acordo com o método $\mathrm{n}^{\circ}$ 08-01 da AACC (1995), em que foram pesados $2 \mathrm{~g}$ de amostra nos cadinhos previamente tarados e colocados em mufla aberta a $600{ }^{\circ} \mathrm{C}$ até total carbonização. Logo após a carbonização, a mufla foi fechada por 2 horas. Em seguida os cadinhos foram retirados da mufla e colocados na estufa a $105^{\circ} \mathrm{C}$ por 5 minutos e posteriormente colocados no dessecador até resfriar à temperatura ambiente. Pesados e feitos os cálculos.

\section{Determinação de proteína}

Multiplicando-se o nitrogênio total por 5,7 conforme o método n 46-13 da AACC (1995). Utilizando como catalisador $\mathrm{Na}_{2} \mathrm{SO}_{4}, \mathrm{CuSO}_{4}$ e Se e titulante $\mathrm{H}_{2} \mathrm{SO}_{4} 0,1 \mathrm{~N}$.

\section{Determinação da fração lipídica}

Determinada por extração com solvente (metanol) em aparelho tipo Soxhlet de acordo com método $n^{\circ} 30-20$ da AACC (1995).

\section{Determinação de carboidratos totais}

O teor de carboidratos totais foi calculado por diferença de acordo com a relação abaixo (Equação 1):

Carboidratos totais $=100-\left(\mathrm{U}_{\text {amostra }}+\mathrm{F} \cdot \mathrm{M}_{\text {amostra }}+\mathrm{F} \cdot \mathrm{P}_{\text {amostra }}+\mathrm{F} \cdot \mathrm{L}_{\text {amostra }}\right)(1)$ em que:

$\mathrm{U}_{\text {amostra }}=$ Umidade da farinha de trigo;

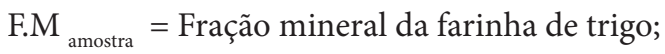

F.P ${ }_{\text {amostra }}=$ Fração proteica da farinha de trigo; e

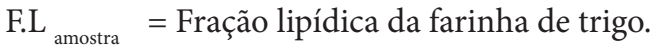

\section{Produção de amido fosforilado}

A modificação para a produção do amido fosforilado foi feita por esterificação do amido in natura com tripolifosfato de sódio (TPS) usando-se o método de Paschall (1964), com algumas modificações. Foi feita uma solução de água destilada com TPS de acordo com cada nível de fosforilação desejado, ou seja, nível I (2,5\%): 4,17 g de TPS em 167,0 mL de água; nível II (5,0\%): 8,34 g de TPS em $167 \mathrm{~mL}$ de água; nível III (10,0\%): 16,70 g de TPS em 167,0 mL de água; nível IV (15,0\%): 25,05 g de TPS em 167,0 mL de água. Após cada dissolução, o $\mathrm{pH}$ foi ajustado para 8,50 , adicionando-se em seguida $100,0 \mathrm{~g}$ de amido de milho com 11,40\% de umidade. Após 30 minutos de agitação, as dispersões foram filtradas a vácuo em funil de Buchner através de papel de filtro comum. Os resíduos sólidos foram levados para secar em estufa com circulação forçada de ar (QUIMIS, modelo 314D222; São Paulo, SP, Brasil) com a temperatura entre 40,0 e $45,0{ }^{\circ} \mathrm{C}$. Em seguida, os sólidos secos foram pulverizados em almofariz e levados a $65,0^{\circ} \mathrm{C}$ por 90 minutos e, posteriormente, a $155,0{ }^{\circ} \mathrm{C}$ por 20 minutos em estufa com circulação forçada de ar.

\section{Purificação do amido de milho fosforilado}

A purificação do derivado de amido no item anterior foi feita conforme o método descrito por Smith e Caruso (1964). Para cada 20,0 g de amido (base seca), foram adicionados 
200,0 mL de água destilada à temperatura ambiente. Esta mistura foi agitada por 15,0 minutos, recuperando-se o amido por filtração a vácuo. Esse procedimento foi realizado até que o teor de sódio no amido recuperado ficasse entre 0,0-5,0 ppm. $\mathrm{O}$ produto resultante da última lavagem foi seco em estufa com circulação forçada de ar a $40,0-45,0^{\circ} \mathrm{C}$, pulverizado em almofariz e passado em peneira de 35,0 mesh $(\phi=0,42 \mathrm{~mm})$.

\section{Determinação do teor de sódio, teor de}

fósforo e do grau de substituição

O teor de sódio no amido in natura e nos amidos modificados foi determinado por potenciometria, com eletrodo específico para sódio, marca Orion, segundo o manual de instrução do fabricante do eletrodo. $\mathrm{O}$ teor de fósforo no amido in natura $\mathrm{e}$ nos modificados foi determinado usando-se o método de Fisk e Subarow (1925). O Grau de Substituição (GS) dos amidos modificados foi determinado em função do teor de fósforo diferencial, em base seca, através da relação abaixo, sugerida por Wurzburg (1989) (Equação 2).

$$
\begin{aligned}
& \text { Grau de substituição (GS) = } \\
& \frac{162(\% \text { Fosfato amostra } / \text { P.M } \text { Fosfato })}{100-\left(\text { P.M } \text { Fosfato }_{\text {f }}-1 /{\mathrm{P} . M_{\text {Fosfato }} \times \% \text { Fosfato }}_{\text {Amostra }}\right)}
\end{aligned}
$$

em que:

Fosfato $_{\text {amostra }}=$ Percentual de fosfato presente na amostra; e
P.M $_{\text {Fosfato }}=$ Peso molecular do fosfato adicionado.

\section{Gelatinização e determinação de amido resistente}

A gelatinização foi feita suspendendo-se os amidos fosforilados em excesso de água destilada, na proporção amido/água de $1 / 10$, elevando-se a temperatura até a ebulição $\left(100,0^{\circ} \mathrm{C}\right)$ sob agitação constante até a formação de um gel para, em seguida, resfriar o gel formado, à temperatura ambiente, levando-o a secar a $40,0^{\circ} \mathrm{C}$ em estufa com circulação forçada de ar, durante 12,0 horas.

A determinação do teor de amido resistente foi realizada pelo método de Berry (1986), onde foram pesados 0,100 $\mathrm{g}$ do amido gelatinizado seco, dissolvendo-o em $10,0 \mathrm{~mL}$ de uma solução de $\alpha$ - amilase $0,2 \%$ em tampão $\mathrm{pH}=6,91$, deixada em banho a $37,0^{\circ} \mathrm{C}$ sob agitação, durante 12 horas. Adicionou-se $35,0 \mathrm{~mL}$ de etanol, misturou-se e deixou-se em repouso por 1 hora, centrifugando (Centrífuga refrigerada da marca SIGMA, modelo 2K15, Berlim, Alemanha) a suspensão (tempo: 20 minutos; $5000 \times$ g), desprezando-se o sobrenadante, lavando-se o resíduo remanescente duas vezes com etanol a $80 \%$, secando-o em estufa com circulação forçada a $60^{\circ} \mathrm{C}$ durante 9 horas. Ao resíduo seco foram adicionados $13,5 \mathrm{~mL}$ de água e $1,5 \mathrm{~mL}$ de hidróxido de potássio $4 \mathrm{M}$, misturados durante 30 minutos, ajustando-se o $\mathrm{pH}$ para 4,5 com ácido acético $2 \mathrm{M}$, adicionado com $1 \mathrm{~mL}$ de uma solução de amiloglucosidase $1,01 \%$, colocando-se a mistura em banho a $65^{\circ} \mathrm{C}$ sob agitação durante 90 minutos. Em seguida o material digerido foi transferido para um balão volumétrico $\mathrm{e}$ tomada uma alíquota para a determinação dos açúcares redutores pelo método de Nelson (1944).

\section{Determinação de açúcares redutores}

O Método descrito por Nelson (1944) foi utilizado para a determinação de açúcares redutores, no qual foram misturados $25 \mathrm{~mL}$ do reagente A (solução de carbonato de sódio anidro + tartarato de potássio + tartarato de potássio + bicarbonato de sódio + sulfato de sódio anidro em $1 \mathrm{~L}$ de água destilada) com $1 \mathrm{~mL}$ do reagente $\mathrm{B}$ (solução de sulfato de cobre pentahidratado + ácido sulfúrico concentrado em $100 \mathrm{~mL}$ ). Para a curva padrão, foram tomadas alíquotas de 0,1 a 1,0 mL da solução padrão de glicose $\left(0,18\right.$ g.L $\left.\mathrm{L}^{-1}\right)$ em tubos de Folin-Wu e completadas a $1 \mathrm{~mL}$ com água destilada. Adicionou-se $1 \mathrm{~mL}$ da mistura acima. A solução é homogeneizada. Os tubos de Folin-Wu são aquecidos em banho-maria a $100^{\circ} \mathrm{C}$, durante 20 minutos. São então resfriados em água corrente até a temperatura ambiente. Em seguida, adicionou-se $1 \mathrm{~mL}$ do reagente $C$ (solução de molibdato de amônio em $450 \mathrm{~mL}$ de água destilada $+21 \mathrm{~mL}$ de ácido sulfúrico concentrado $+3 \mathrm{~g}$ de arseniato de sódio em $25 \mathrm{~mL}$ de água). Misturou-se bem e completou-se o volume a $25 \mathrm{~mL}$ com água destilada. Após homogeneização, foi feita a leitura da transmitância das soluções a $450 \mathrm{~nm}$.

\section{Determinação das propriedades de pasta dos amidos de milho in natura e fosforilados}

As propriedades de pasta foram determinadas através do viscoamilógrafo (Marca Brabender; Duisburg, Alemanha) segundo metodologia descrita pela AACC (1995). Foram feitas suspensões usando-se $40 \mathrm{~g}$ de amido in natura ou fosforilado em $460 \mathrm{~mL}$ de água a pH 7,5. As suspensões foram aquecidas a uma taxa de $1,5^{\circ} \mathrm{C} /$ minuto a partir de $25^{\circ} \mathrm{C}$ até a temperatura de $95^{\circ} \mathrm{C}$, sendo, posteriormente, mantidas nesta temperatura por 30 minutos. Em seguida, as pastas foram resfriadas gradativamente $\left(1,5^{\circ} \mathrm{C} /\right.$ minuto $)$ até a temperatura de $50,0^{\circ} \mathrm{C}$. Dos amilogramas obtidos foram determinados os seguintes parâmetros:

- Temperatura de pasta - temperatura em ${ }^{\circ} \mathrm{C}$ na qual a curva de viscosidade da pasta inicia a formação da curva ascendente;

- Viscosidade máxima - valor máximo da viscosidade da pasta em U A (unidades amilográficas) na etapa de aquecimento; $\mathrm{e}$

- Viscosidade a $50{ }^{\circ} \mathrm{C}$ - valor da viscosidade da pasta em UA no final do período de resfriamento (temperatura de $\left.50^{\circ} \mathrm{C}\right)$.

\section{Análise estatística}

A análise estatística para a determinação das diferenças significativas em nível de 5\% dos resultados encontrados, foi realizada através do software SAS Institute, Carry, NC (SAS, 2002).

\section{Resultados e discussão}

\subsection{Composição centesimal dos amidos}

As composições centesimais dos amidos de milho e trigo encontram-se na Tabela 1 e os resultados encontrados estão de acordo com a tabela de composição de alimentos do 
Departamento de Agricultura dos Estados Unidos (USDA, 2006).

\subsection{Nível de fósforo residual}

Para usos alimentícios, o Food and Drug Administration (FDA, 2007) estabelece que o uso do tripolifosfato de sódio é seguro desde que seja utilizado de acordo com as boas práticas de fabricação. A norma brasileira, através da resolução (RDC) n. 234/2002 da agência Nacional de Vigilância Sanitária (ANVISA), permite uma concentração residual de $0,1 \%$ de fósforo ou $0,5 \%$ de $\mathrm{P}_{2} \mathrm{O}_{5}$, quando se usa o tripolifosfato de sódio (TPS) na modificação de amidos (BRASIL, 2002).

Os teores residuais máximos de fósforo encontrados no amido de milho modificado pela adição de tripolifosfato estão de acordo com a legislação brasileira conforme mostra a Tabela 2, enquanto que para o amido de trigo modificado, apenas os níveis de adição de 2,5 e $5 \%$ não ultrapassam os valores permitidos pela legislação. O nível inicial de adição de tripolifosfato de sódio $(2,5 \%)$ foi escolhido usando-se como referência o valor recomendado pelo próprio método de Paschall (1964) e tendo como limite o nível de adição de 15,0\% em função da dificuldade da filtração do amido após as lavagens realizadas para a redução do teor de sódio no produto.

\subsection{Grau de substituição e teores de amido resistente nos amidos modificados}

Os graus de substituição dos amidos de milho e trigo apresentaram valores crescentes com os níveis de adição de TPS adicionado (Tabela 3 ), observando-se maiores valores para o amido de trigo provavelmente por uma maior afinidade deste amido com o TPS. É possível que esse comportamento

Tabela 1. Composição centesimal dos amidos de milho e trigo.

\begin{tabular}{lcc}
\hline Componentes & Milho $(\%)^{\star}$ & Trigo $(\%)^{\star}$ \\
\hline Umidade & $11,7 \pm 0,72^{\mathrm{a}}$ & $11,40 \pm 0,407^{\mathrm{a}}$ \\
Fração protéica & $0,65 \pm 0,05^{\mathrm{a}}$ & $0,575 \pm 0,001^{\mathrm{b}}$ \\
Fração lipídica & $1,195 \pm 0,46^{\mathrm{a}}$ & $1,20 \pm 0,300^{\mathrm{a}}$ \\
Fração mineral & $0,02 \pm 0,006^{\mathrm{b}}$ & $0,197 \pm 0,002^{\mathrm{a}}$ \\
Carboidrato & $86,97 \pm 0,60^{\mathrm{a}}$ & $86,628 \pm 0,55^{\mathrm{a}}$ \\
\hline
\end{tabular}

${ }^{*}$ Média \pm desvio padrão; $\mathrm{n}=3 ; \alpha=0,95$; e letras iguais em uma mesma coluna, indica que a nível de 5\%, não existe diferença significativa entre as médias.

Tabela 2. Teor de fósforo residual dos amidos de trigo e milho modificados.

\begin{tabular}{ccc}
\hline TPS Adicionado (\%) & \multicolumn{2}{c}{ Fósforo residual $(\%)^{\star}$} \\
\cline { 2 - 3 } & Amido de milho & Amido de trigo $^{1}$ \\
\hline 2,50 & $0,0726 \pm 0,0001^{\mathrm{a}}$ & $0,0550 \pm 0,0003^{\mathrm{b}}$ \\
5,00 & $0,0822 \pm 0,0002^{\mathrm{b}}$ & $0,1048 \pm 0,0004^{\mathrm{a}}$ \\
10,00 & $0,0972 \pm 0,0001^{\mathrm{b}}$ & $0,2049 \pm 0,0003^{\mathrm{a}}$ \\
15,00 & $0,0980 \pm 0,0002^{\mathrm{b}}$ & $0,2407 \pm 0,0002^{\mathrm{a}}$ \\
\hline
\end{tabular}

${ }^{*}$ Média \pm desvio padrão; $\mathrm{n}=3 ; \alpha=0,95 ;{ }^{1}$ Fonte: amido de trigo, Liberato (2002); letras iguais em uma mesma coluna, indica que a nível de $5 \%$, não existe diferença significativa entre as médias. possa ser explicado pela diferença no teor de amilose e pela distribuição dos grupos fosfato entre a amilose e amilopectina (LIU; RAMSDEM; CORKE, 1999) entre os amidos de milho e trigo, limitados a um nível máximo de adição de 15,0\% de TPS, pois, para ensaios com concentrações acima deste valor, ocorreu a gelatinização quase instantânea à temperatura ambiente nas condições de ensaio.

O aumento do teor de amido resistente com a introdução de grupos fosfatos (Grau de Substituição) nas moléculas de amido está de acordo com resultados semelhantes encontrados por Seib e Woo (1999) e pode ser visto nas Tabelas 4 e 5. Nestas tabelas, podemos observar a variação de teor de amido resistente quando se aumenta o teor de tripolifosfato de sódio, para os amidos de milho e trigo, observando-se uma formação de amido resistente bastante significativa. Os teores de amido resistente aumentaram com os graus de substituição de ambos os amidos, observandose valores inferiores de amido resistente para todos os graus de substituição do amido de milho quando comparados ao de trigo, exceto para o primeiro nível de substituição no amido de milho in natura, provavelmente pelo fato dele conter um teor de fosfato inicial maior que o amido de trigo.

A explicação para um aumento no percentual de amido resistente, quando se aumenta o teor de grupos fosfato no amido, parece ser a dificuldade das enzimas amilolíticas em romper as

Tabela 3. Grau de substituição dos amidos de milho e trigo modificados.

\begin{tabular}{ccc}
\hline TPS Adicionado (\%) & \multicolumn{2}{c}{ Grau de substituição (GS) } \\
\cline { 2 - 3 } & Amido de milho & Amido de trigo $^{1}$ \\
\hline 2,50 & $0,0036^{\mathrm{a}}$ & $0,0029^{\mathrm{b}}$ \\
5,00 & $0,0042^{\mathrm{b}}$ & $0,0055^{\mathrm{a}}$ \\
10,00 & $0,0047^{\mathrm{b}}$ & $0,0108^{\mathrm{a}}$ \\
15,00 & $0,0052^{\mathrm{b}}$ & $0,0127^{\mathrm{a}}$ \\
\hline
\end{tabular}

${ }^{1}$ Fonte: Amido de trigo, Liberato (2002); letras iguais em uma mesma coluna, indica que a nível de $5 \%$, não existe diferença significativa entre as médias.

Tabela 4. Variação do teor de amido resistente do amido de milho com o aumento dos graus de substituição por grupos fosfato.

\begin{tabular}{cc}
\hline Grau de substituição & Amido resistente $(\%)^{\star}$ \\
\hline 0,0036 & $24,36 \pm 0,031$ \\
0,0042 & $25,17 \pm 0,150$ \\
0,0047 & $26,38 \pm 0,020$ \\
0,0052 & $28,40 \pm 0,250$ \\
\hline
\end{tabular}

${ }^{*}$ Média \pm desvio padrão; $\mathrm{n}=3$; e $\alpha=0,95$.

Tabela 5. Variação do teor de amido resistente do amido de trigo com o aumento dos graus de substituição por grupos fosfato.

\begin{tabular}{cc}
\hline Grau de substituição & Amido resistente $(\%)^{* 1}$ \\
\hline 0,0029 & $30,46 \pm 0,035$ \\
0,0055 & $36,01 \pm 0,042$ \\
0,0108 & $42,23 \pm 0,040$ \\
0,0127 & $46,69 \pm 0,031$ \\
\hline
\end{tabular}

${ }^{*}$ Média \pm desvio padrão; $\mathrm{n}=3 ; \alpha=0,95 ; \mathrm{e}^{1}$ Fonte: Liberato (2002). 
ligações glicosídicas da amilose e amilopectina, pela formação de uma enorme nuvem eletrônica em torno dessas ligações, impedindo a quebra dessas moléculas (LIBERATO, 2002).

\subsection{Propriedades de pasta dos amidos modificados}

Foram realizados amilogramas para a determinação das propriedades de pasta do amido de milho em três circunstâncias: o amido in natura, com 5,0\% de TPS adicionado e com $15,0 \%$ de TPS adicionado. Os resultados amilográficos estão representados na Tabela 6 e 7.

$\mathrm{O}$ amido de milho in natura apresentou uma viscosidade máxima superior ao amido de trigo in natura, indicando uma maior presença de forças intermoleculares no instante em que a viscosidade máxima foi observada. Amidos de cereais como o milho e o trigo com elevados teores de amilose, lipídios e fosfolipídios, apresentam elevadas temperaturas de pasta, baixo pico de viscosidade, maior resistência ao cisalhamento e alta tendência à retrogradação que podem ser atribuídos ao complexo amilose-lipídios (FRANCO et al., 2002), que pode beneficiar as propriedades sensoriais e de firmeza quando aplicados em formulações de pães.

O comportamento apresentado pelo amido de trigo nos níveis de adição de TPS mostrou uma redução nas temperaturas de pasta e uma elevação nos picos de viscosidade, fato também observado por Lim e Seib (1993). O aumento da viscosidade no amido modificado quando comparado ao amido de trigo in natura indica uma possível maior interação entre os componentes dos grânulos na presença dos grupos fosfato. $\mathrm{O}$ amido de milho em ambos os níveis de adição de TPS (5 e 15\%) apresentaram picos de viscosidade inferiores ao amido de trigo modificado, provavelmente por causa de uma menor interação dos grupos fosfato com os componentes desse amido.

No amido de milho não houve nenhuma relação entre o conteúdo de fósforo, os picos de temperatura e as temperaturas

Tabela 6. Parâmetros amilográficos dos amidos de milho in natura, com 5,0\% de TPS adicionado e 15,0\% de TPS adicionado.

\begin{tabular}{lccc}
\hline \multicolumn{1}{c}{ Parâmetros } & \multicolumn{3}{c}{ Amido de milho } \\
\cline { 2 - 4 } & In natura & $5,0 \%$ de TPS & $15,0 \%$ de TPS \\
\hline Viscosidade máxima (UA) & 550 & 1000 & 750 \\
Viscosidade a $50{ }^{\circ} \mathrm{C}(\mathrm{UA})$ & 1040 & 1160 & 1040 \\
Temperatura de pasta $\left({ }^{\circ} \mathrm{C}\right)$ & 49,5 & 49,5 & 49,5 \\
\hline
\end{tabular}

UA - Unidades amilográficas; $\mathrm{e}^{\circ} \mathrm{C}$ - Graus celsius.

Tabela 7. Parâmetros amilográficos dos amidos de trigo in natura, na fase dois e na fase quatro fosforilados com TPS.

\begin{tabular}{lccc}
\hline \multicolumn{1}{c}{ Parâmetros } & \multicolumn{3}{c}{ Amido de trigo } \\
\cline { 2 - 4 } & In natura & $5,0 \%$ de TPS & $15,0 \%$ de TPS \\
\hline Viscosidade máxima (UA) & 264 & 1259 & $>2980$ \\
Viscosidade a $50{ }^{\circ} \mathrm{C}(\mathrm{UA})$ & 596 & 2130 & 3290 \\
Temperatura de pasta $\left({ }^{\circ} \mathrm{C}\right)$ & 87,5 & 54,6 & 46,8 \\
\hline
\end{tabular}

UA - Unidades amilográficas; $\mathrm{e}^{\circ} \mathrm{C}$ - Graus celsius. de viscosidade da pasta. Esses resultados sugerem que com o aumento dos níveis de fósforo não houve um incremento na gelatinização do amido, embora tenha sido facilitada, mas sim o inchaço das amilopectinas nas regiões onde os grânulos fósforilados foram encontrados. Isto pode acontecer na fase posterior à gelatinização, quando a hidratação e o inchaço do grânulo se dão na região amorfa do grânulo de amido (KARIM et al., 2007).

\section{Conclusões}

Levando-se em conta os experimentos realizados e seus resultados, podemos concluir que:

É possível a obtenção dos amidos de milho e trigo fosforilados com teores de fósforo aceitáveis na indústria alimentícia usando-se o método de Paschall (1964) adaptado. Os grupos fosfato introduzidos durante o processo de modificação aumentaram a viscosidade máxima, a viscosidade a $50{ }^{\circ} \mathrm{C}$ e mantiveram constante a temperatura de pasta no amido de milho à proporção que os graus de substituição foram aumentados.

O teor de amido resistente às enzimas amilolíticas também aumentou com o incremento no grau de substituição.

\section{Referências bibliográficas}

AMERICAN ASSOCIATION OF CEREAL CHEMISTS - AACC. Approved methods of the American Association of Cereal Chemists. 11th ed. St. Paul, Minnesota, 1995.

BERRY, C. S. Resistant starch: formation and measurement of starch that survives exhaustive digestion with amilolitic enzymes during the determination of dietary fyber. Journal of Cereal Science, v. 4, n. 4, p. 301-314, 1986.

BRASIL. Agência Nacional de Vigilância Sanitária. Resolução RDC n. 234, de 19 de agosto de 2002. Regulamento técnico sobre aditivos utilizados segundo as boas práticas de fabricação e suas funções. Diário Oficial da União, Poder Executivo, Brasília, DF, 21 de agosto de 2002.

FISK, C. H.; SUBBAROW, Y. The colorimetric determination of phosphorus. Journal of Biological Chemistry, v. 66, n. 2, p. $375-400,1925$.

FOOD AND DRUG ADMINISTRATION - FDA. Food starch modified: code of federal regulation. Washington, 2007. (v. 3)

FRANCO, C. M. L. et al. Structural and functional characteristics of selected soft wheat starches. Cereal Chemistry, v. 79, n. 2, p. 243-248, 2002.

KARIM, A. A. et al. Effects of phosphorus contents on the gelatinization and retrogradation of potato starch. Journal of Food Science, v. 72, n. 2, p. C132-C138, 2007.

LIBERATO, M. C. T. C. Obtenção, propriedades e aplicação do amido resistente de trigo. Ceará, 2002. 92 p. Tese (Mestrado) Universidade Federal do Ceará - UFC.

LIM, S.; SEIB, P. A. Preparation and pasting properties of wheat and waxy corn starch phosphates. Cereal Chemistry, v. 70, n. 2, p. 137-144, 1993.

LIU, H.; RAMSDEN, L.; CORKE, H. Physical properties and enzymatic digestibility of phosphorylated ae, wx, and normal maize starch prepared at different $\mathrm{pH}$ levers. Cereal Chemistry, v. 76, n. 6, p. 938-943, 1999. 
NELSON, N. A photometric adaptation of the somogyi method for the determination of glucose. Journal of Biological Chemistry, v. 153, p. 375-380, 1944.

NODA, T. et al. Starch phosphorus content in potato (Solanum tuberosum L.) cultivars and its effect on other starch properties. Carbohydrate Polymers, v. 68, n. 4, p. 793-796, 2007.

PASCHALL, E. F. Phosphation with inorganic phosphate salts. In: WHISTLER, R. L. (ed.). Methods in carbohydrates chemistry. New York: Academic Press, 1964. p. 294-296. (v. 4)

RUTENBERG, M. W.; SOLAREK, V. Starch derivatives: production and uses. In: WHISTLER, R. L.; BEMILLER, J. N.; PASCHALL, E. F. (eds.). Starch: chemistry and tecnology. 2nd ed. U.S.: Academic Press, 1984. p. 312-388.

SAS Institute. JMP Software. Version 5. Carry, 2002.

SEIB, P. A.; WOO, K. Food grade starch resistant to $\boldsymbol{\alpha}$-amylase and method of preparing the same. United States n. PI 5855946, 01 maio 1999 .
SMITH, R. J.; CARUSO, J. Determination of phosphorus. In: WHISTLER, R. L. (Ed.). Methods in carbohydrate chemistry: starch. New York: Academic Press, 1964. p. 42-46. (v. 4)

TEIXEIRA, M. A. V. et al. Ocorrência e caracterização do amido resistente em amidos de milho e de banana. Ciência e Tecnologia de Alimentos, v. 18, n. 2, p. 246-253, 1998.

UNITED STATES DEPARTMENT OF AGRICULTURE - USDA. Nutritive Value of Foods. Estados Unidos, 2006. Disponível em: <www.usda.gov/>. Acesso em: 15 jun. 2006.

WOLF, M. J. Wheat starch isolation. In: WHISTLER, R. E. Methods in carbohydrates

chemistry. New York: Academic Press, 1964. p. 18. (v. 4)

WURZBURG, O. B. Modified starches: properties and uses. 4 ed. Boca Raton, Flórida: CRC Press Inc., 1989. 288 p. 